\title{
Equilibrium Locations in a Spatial Model with Sequential Entry in Real Time
}

\author{
Luca Lambertini \\ Dipartimento di Scienze Economiche \\ Università degli Studi di Bologna \\ Strada Maggiore 45 \\ 40125 B ologna, I taly \\ phone +39-51-6402600 \\ fax + 39-51-6402664 \\ e-mail lamberti@spbo.unibo.it
}

\begin{abstract}
A bstract
I describe the entry process in a spatial market over an in..nite time horizon. I show that, as long as the strategy space at the location stage is unbounded, the results derived from the single-period Stackelberg model of entry coincide with those obtained in the in..nite horizon model. On the contrary, if the strategy space is bounded, then the later the follower enters, the closer to the center of the market the leader locates at the initial date.
\end{abstract}

J EL Classi..cation: L 13, 031

K eywords: location leadership, entry, time

\footnotetext{
${ }^{x}$ A cknowledgments. I thank Raimondello Orsini and Carlo Scarpa for useful comments. The usual disclaimer applies.
} 


\section{Introduction}

The issue of entry and entry deterrence has received wide attention in the literature on spatial competition, the research carried out in this ..eld being focussed upon three main topics, namely, (i) the analysis of sequential entry by single-product ..rms (Hay, 1976; Prescott and V isscher, 1977; Lane, 1980; Eaton and Wooders, 1985; Neven, 1987); (ii) the existence of pure pro..ts in the long-run (Eaton, 1976; Eaton and Lipsey, 1978); and (iii) the strategic use of capital and/ or brand proliferation as a barrier to entry (Schmalensee, 1978; Eaton and Lipsey, 1980; J udd, 1985; Bonanno, 1987). Most of the existing literature on sequential entry makes use of a single-period setting where the sequential nature of the game is captured by the assumption that earlier movers act as Stackelberg leader, while later movers act as Stackelberg followers. Hence, the relevance of time in determining ..rms' decisions is summarised by the fact that, if a ..rm moves (i.e., enters) ..rst and another moves (i.e., enters) second, the former can use strategically the information contained in the best reply function of the latter.

A well known result derived by this approach in the linear model of spatial dixerentiation with single-product ..rms is that a monopolist locates in the middle of the product space. This position is also optimal when a second ..rm enters, as long as the resulting degree of product dixerentiation is su $\$$ cient to ensure that no relocation incentive appears for the incumbent. ${ }^{1}$ Otherwise, the leader should anticipate this event and either (i) choose a dixerent location from the outset, if relocation costs are prohibitively high; or (ii) relocate as soon as the rival enters, if this can be done costlessly.

The aim of this note is to highlight the infuence of time in determining the ..rst entrant's decision as to location in the product space, under the assumption that any relocation after the rival's entry is impossible. I show that, if ..rms can choose any amount of reciprocal product dixerentiation, time is irrelevant and the single-period Stackelberg model oxers a good description of the entry process. If, instead, the amount of dixerentiation that can be supplied at equilibrium is bounded, and coincides with the space of

\footnotetext{
${ }^{1}$ For the model with quadratic transportation costs, see Bonanno (1987); N even (1987); Tabuchi and Thisse (1995); and Lambertini (1997). The same analysis is carried out by Anderson (1987) under the assumption of linear transportation costs.
} 
consumer preferences, then the ..rst entrant's equilibrium location is closer to the optimal monopoly location, the later is the date at which a second ..rm is expected to enter the market; conversely, the leader's location is closer to the simultaneous one-shot equilibrium location, the earlier the rival is expected to enter. This, in turn, entails that the degree of dixerentiation at equilibrium is negatively related with the amount of time along which the ..rst entrant expects to remain a monopolist.

The remainder of the paper is organised as follows. The basic model and the price stage are described in section 2. The entry process is laid out in section 3. Finally, concluding remarks are in section 4.

\section{Setup and price behaviour}

The basic model shares many features with that introduced by d'A spremont, Gabszewicz and Thisse (1979). I consider a market for horizontally dixerentiated products where consumers are uniformly distributed with unit density along the unit interval $[0 ; 1]$. Let this market exist over t $2[0 ; 1)$ : T wo pro.tt-maximising ..rms, labelled as 1 and 2, sequentially choose locations $x_{1}$ and $x_{2}$ and compete in prices simultaneously as soon as both are in the market. I will consider both the case where ..rms are to locate within the unit interval, and the case where they are free to locate also outside $[0 ; 1]$. Accordingly, in the remainder of the paper, on the basis of the symmetry of the model, I assume alternatively that $x_{1} 2[0 ; 1=2]$ and $x_{2} 2[1=2 ; 1]$; or $x_{1} 2[i 1 ; 1=2]$ and $x_{2} 2[1=2 ; 1]:^{2}$ Firm 1 enters at $t=0$, while ..rm 2 enters at $i 2(0 ; 1):$ I assume that $i$ is certain and known from the outset to both players. E ntry entails a sunk cost $F$, such that location must be chosen once and for all at the time of entry in order to maximise the discounted fow of pro..ts from that instant onwards. This ..xed cost may be thought of as an irreversible $R \& D$ investment undertaken at $t=0$. Such $R \& D$ activity results in a new product immediately for ..rm 1 and at time $i$ for ..rm 2 . Unit production cost is assumed to be constant and equal across varieties. Without further loss of generality, I normalise it to zero. Throughout the time horizon considered, both ..rms have the same discount rate $1 / 2$

The generic consumer located at a $2\left[\mathrm{x}_{1} ; \mathrm{x}_{2}\right]$ buys one unit of the good, enjoying the following net surplus:

\footnotetext{
${ }^{2}$ This assumption is meant to exclude the possibility of leapfrogging by either ..rm.
} 


$$
\mathrm{U}=\mathrm{s} \text { i } \mathrm{p}_{\mathrm{i}} \text { i } c\left(\mathrm{x}_{\mathrm{i}} \mathrm{i} \quad \mathrm{a}\right)^{2}, 0 ; \quad \mathrm{i}=1 ; 2
$$

where $x_{i}$ and $p_{i}$ are ..rm's $i$ location and mill price, respectively, and $c>0$ is the transportation cost rate. In the remainder of the paper, I suppose that the reservation price $s$ is never binding, so that full market coverage always obtains. To ensure this, it must be assumed that s , 3c (cf. Bonanno, 1987; Harter, 1993). Let the demand function for ..rm i be $y_{i}^{k} 2[0 ; 1]$ in each period t; with $y_{i}^{k}=1 i y_{j}^{k}$ : Then, ..rm i's instantaneous pro..t function is $1 /$ k $=p_{i}^{k} y_{i}^{k}$; where superscript $k=m$; $d$ indicates the relevant market regime (monopoly or duopoly).

A s long as the ..rst ..rm to enter the market (..rm 1) remains a monopolist, her per period demand function is $y_{1}^{m}=1$ : Hence, her pro..t function is $1 / m=p_{1}^{m}$; and she ..nds it optimal to set a price such that the farthest consumer's net surplus at equilibrium is nil. Given the above assumption about the strategy space in locations, such consumer is at the right extreme of the segment, and the monopoly price and pro..ts are

$$
p_{1}^{m}=s ; \quad c\left(1 ; x_{1}\right)^{2}=1 / m_{1}^{m}\left(x_{1}\right):
$$

Consider now the duopoly setting. One can easily derive from (1) the location of the consumer who is indixerent between the two goods at generic price and location pairs,

$$
s \text {; } p_{1}^{d} ; c\left(a ; x_{1}\right)^{2}=s ; p_{2}^{d} ; c\left(x_{2} ; a\right)^{2} \text {; }
$$

as well as the demand functions, provided a $2\left[\mathrm{x}_{1} ; \mathrm{x}_{2}\right]:^{3}$

$$
y_{1}^{d}=\frac{p_{2}^{d} i p_{1}^{d}+c\left(x_{2}^{2} ; x_{1}^{2}\right)}{2 c\left(x_{2} i x_{1}\right)} ; \quad y_{2}^{d}=1 ; y_{1} \text { : }
$$

Suppose ..rms set prices simultaneously. The Nash equilibrium in prices, for a given pair of locations, is given by

$$
p_{1}^{d}=\frac{c\left(x_{2}^{2}+2 x_{2} ; 2 x_{1} ; x_{1}^{2}\right)}{3} ; p_{2}^{d}=\frac{c\left(x_{1}^{2} ; 4 x_{1}+4 x_{2} ; x_{2}^{2}\right)}{3}:
$$

As a result, per period individual pro..t functions simplify as follows:

$\left.1 / 1 / x_{1} ; x_{2}\right)=\frac{c\left(x_{2} ; x_{1}\right)\left(x_{1}+x_{2}+2\right)^{2}}{18} ; 1 / 8\left(x_{2} ; x_{1}\right)=\frac{c\left(x_{2} ; x_{1}\right)\left(x_{1}+x_{2} ; 4\right)^{2}}{18}$ :

\footnotetext{
${ }^{3}$ If this condition is not met, e.g., if the indixerence condition is written under the assumption that a $2\left(\mathrm{x}_{2} ; 1\right]$; then it can be immediately veri..ed that the location of the indixerent consumer is unde.ned.
} 


\section{The entry game}

I assume that the game takes place in continuous time. F irm 2 enters at date $i$, in a location $x_{2}, x_{1}$; which, in turn, must be chosen once and for all by ..rm 1 at date 0 : In describing ..rm's choice of location, the ..xed $R \& D$ cost $F$ can be disregarded. The objective function of ..rm 1 is

$$
i_{1}=Z_{0}^{Z_{i}}\left[1 / 4_{1}^{m}\left(x_{1}\right) \phi e^{i^{1 / k}}\right] d t+Z_{i}^{Z_{1}}\left[1 / \frac{d}{4}\left(x_{1} ; x_{2}\right) \phi e^{i^{1 / 5}}\right] d t ;
$$

while the objective function of ...rm 2 is

$$
i_{2}=Z_{i}^{Z_{1}}\left[1 / \frac{d}{2}\left(x_{2} ; x_{1}\right) \phi e^{i \frac{1 / 2}{2}}\right] d t \text { : }
$$

Obviously, it would be in ..rm 2's interest to enter as early as possible (conversely, ...rm 1 would like to remain a monopolist as long as possible). However, an entry date $i>0$ can result either from unsuccessful $R \& D$ activity by ..rm 2 between 0 and $i$; or from a broad patent protection sheltering the monopoly power of ..rm 1 over the same time span. I intentionally leave the explicit modelization of these elements out of the picture, in order to focus upon the descriptive power of single-period Stackelberg games versus multiperiod entry games. It is reasonable to assume that, in maximising (7), ..rm 1 acts as a Stackelberg leader by taking into account the best reply of ...rm 2, implicitly de..ned by the ..rst order condition for the maximisation of (8) w.r.t. $x_{2}$ : Hence, the leader's problem consists in maximising (7) under the following constraint:

$$
3 x_{2}^{2} \text { i } x_{1}^{2} \text { i } 16 x_{2}+2 x_{1} x_{2}+16=0
$$

i.e., either $x_{2}=4 i x_{1}$ or $x_{2}=\left(x_{1}+4\right)=3$ : As is well known (Anderson, 1988; L ambertini, 1997), products behave as strategic complements, and this suф ces to establish that the correct best reply of ..rm 2 is $x_{2}=\left(x_{1}+4\right)=3$ :

Consider ..rst the unconstrained case. I am going to prove the following:

Theorem 1 Assume (i) $x_{1} 2[i 1 ; 1=2]$ and $x_{2} 2[1=2 ; 1]$ and (ii) ..rm 1 acts as a Stackelberg leader in locations. Then, in equilibrium, $x_{1}=1=2$ and $x_{2}=3=2$ for all $i 2[0 ; 1)$ :

P roof. Observe that, in the unconstrained location game considered here, ..rms' behaviour is dictated by ..rst order conditions which replicate those of 
the well known single-period problem, in that, when ..rm 2 enters at time $i$; we know that $x_{2}=\left(x_{1}+4\right)=3$ and

$$
\operatorname{sign} \frac{@ 1}{@ \mathrm{x}_{1}}=\operatorname{sign} \frac{@ / 4}{@ \mathrm{x}_{1}} \text { : }
$$

As a result, ..rm 1 locates in $x_{1}=1=2$ at date 0 , which is optimal independently of $i$ : Firm 1's equilibrium per period pro..ts are $1 / \mathrm{m}^{\mathrm{n}}=\mathrm{s} i \mathrm{c}=4$ for all t $2[0 ; i)$ and $1 / \alpha_{1}=8 c=9$ for all t $2[i ; 1)$ : Firm 2 's equilibrium per period pro.ts are $1 / \mathrm{d}=2 \mathrm{c}=9$ for all $\mathrm{t} 2[i ; 1)$ : Hence, this model replicates the static one (see Tabuchi and Thisse, 1995; Lambertini, 1997).

Consider now the constrained case. The following holds:

Theorem 2 Assume (i) $x_{1} 2[0 ; 1=2]$ and $x_{2} 2[1=2 ; 1]$ and (ii) ..rm 1 acts as a Stackelberg leader in locations. Then, in equilibrium,

$$
\begin{aligned}
& x_{1}=\frac{13 i 18 e^{1 / 2}+2^{p} \overline{13 i 90 e^{1 / 2}+81^{21 / 2}}}{3} \text { for all } i 2 \frac{\tilde{A}}{\ln (13=12)} ; \frac{\ln (107=72) !}{1 / 2} ; \\
& x_{1}=0 \text { for all } i 2 \quad 0 ; \frac{\ln (13=12)}{1 / 2}^{\#} \text {; } \\
& x_{1}=\frac{1}{2} \text { for all } i 2 \frac{\ln (107=72)}{1 / 2} ; 1 \text {; } \\
& x_{2}=1 \text { for all } i 2[0 ; 1) \text { : }
\end{aligned}
$$

Proof. Given the boundaries to the strategy space, $x_{2}=1$ : The ..rst order condition for ..rm 1 at the location stage is then

$$
\frac{Q_{1}}{Q_{1}}=\frac{c\left(36 e^{1 / 2}+2\left(13 i 18 e^{1 / 2}\right) x_{1} i \quad 3 x_{1}^{2} i \quad 39\right)}{18^{1 / e^{1 / 2}}}=0 ;
$$

whose roots are

$$
\begin{aligned}
& x_{1 A}=\frac{13 i 18 e^{1 / 2} i 2^{p} \overline{13 i 90 e^{1 / 2}+81 e^{e^{1 / 2}}}}{3} ; \\
& x_{1 B}=\frac{13 i 18 e^{1 / 2}+2^{p} \overline{13 i 90 e^{1 / /}+81 e^{e^{2 / /}}}}{3}:
\end{aligned}
$$


The above roots are real if

$$
13 \text { i } 90 \mathrm{e}^{1 / 2}+81 \mathrm{e}^{2 \frac{1}{2}}, 0 \text {; }
$$

i.e., if $1 / 2, \ln \left[\left(5+2^{p} \overline{3}\right)=9\right]$, which is al ways true in that $\left(5+2^{p} \overline{3}\right)=9<1$. It is immediate to check that the leader's location is given by $x_{1 B}$; in that @i $1=@ x_{1}^{2}<0$ in $x_{1 B}$ only, and

$$
\lim _{i ! 0} x_{1 B}=i \frac{1}{3}
$$

which coincides with the leader's best reply to $x_{2}=1$ in the singleperiod unconstrained model. For any given $1 / 3 x_{1 B}$ is increasing and concave in $i$; with $x_{1 B}=0$ when $i=\ln (13=12)=1 / 7$ and $x_{1 B}=1=2$ when $i=\ln (107=72)=1 / 2$ This entails that $x_{1}=0$ for all $i 2\left[0 ; \ln (13=12)=1 / 1 ; x_{1}=x_{1 B}\right.$ for all i $2\left[\ln (13=12)=1 / 2 ; \ln (107=72)=1 / 1\right.$; and, ..nally, $x_{1}=1=2$ for all i 2 $[\ln (107=72)=12 ; 1)$ :

Theorem 1 states that, as long as the strategy space at the location stage is unbounded, no loss of information on ..rms' behaviour is attached to the single-period Stackelberg metaphor usually adopted to describe the entry process. On the contrary, Theorem 2 shows that, if the strategy space is bounded, then time matters in determining the leader's location as a function of the date at which the follower enters the market. If such entry takes place early enough, the leader chooses not to exploit fully her own monopoly power over the period $[0 ; i)$; and locates at 0 from the outset; otherwise, if entry is late enough, the opposite happens. In general, the later the follower enters the market, the closer to $1=2$ the leader locates at date 0: The straightforward implication of this result is that the singleperiod Stackelberg modelization of the sequential location choice oxers a good description of the entry process if and only if the time span over which the ..rst entrant remains a monopolist is long enough.

As Theorem 2 highlights, the extent of product dixerentiation $x_{2} i x_{1}$ that we expect to observe at equilibrium is smaller, the later the follower enters the market. Then, a relevant corollary of Theorem 2 is the following:

Corollary 1 If the strategy space at the location stage is bounded, then product dixerentiation at equilibrium is non-increasing in $i$ : 
Finally, the situation where the incumbent may relocate costlessly can be considered. If products can be redesigned freely at any point in time, which could be the case if no sunk investment were required, then the incumbent would (i) locate at $1=2$ for all t $2[0 ; i)$; and relocate to $x_{1}=0$ from $i$ onwards, if the location space is [0; 1$]$; (ii) locate at $1=2$ forever, if ..rms can choose any point along the real axis, also outside the boundaries of the linear city. Hence, without sunk costs, the single-period approach usually adopted in most of the existing literature involves no signi..cant loss of information on the optimal behaviour of ...ms.

\section{Concluding remarks}

The foregoing analysis has stressed the importance of real time in explaining ..rms' behaviour as to product characteristics and the resulting degree of dixerentiation. In particular, the main ..ndings are that (i) if the strategy space is unbounded, the in..nite horizon model and the single period model yield qualitatively similar results; (ii) if, instead, ..rms are compelled to locate within the consumer preference space, then the ..rst entrant's location is closer to the middle of the market, the later is the date of entry of the rival ..rm, and conversely. Hence, if the ..rst innovator expects to stand alone on the market place for a long time, the equilibrium con..guration of the location stage closely recalls the familiar Stackelberg equilibrium of a singleperiod model. Otherwise, when the entry date of the follower is early enough, equilibrium locations are the same as under simultaneous entry.

These results have some relevant consequences on our ability to describe such aspects of ..rms' behaviour, as their $R \& D$ activities to discover and introduce new products. This issue is tackled by Harter (1993) in the quadratic transportation cost version of the linear model. He assumes that there are no externalities to the $R \& D$, so that the ..rms' discovery dates are independent. Each ..rm bears a ..xed cost, which is sunk at the beginning of the research activity, plus a constant cost in each period, during the time interval over which she continues to undertake her $R \& D$ exort. In his analysis, Harter considers only location-speci..c $R \& D$ activities, and focuses upon the case where the ..rst innovator locates in the middle point of the market, and the second innovator must evaluate whether to discontinue her $R \& D$ or not, and, if not, she locates at one of the extremes. In the light of the above results, this kind of investigation can be recast into a picture where $R \& D$ 
is not location-speci..c and each ..rm chooses location according to both the likelihood of entering ..rst and the expected date at which the other ..rm would innovate.

\section{R eferences}

[1] Anderson, S. (1987), "Spatial Competition and Price Leadership", International J ournal of Industrial Organization, 5, 369-398.

[2] B onanno, G. (1987), "Location Choice, Product Proliferation and Entry Deterrence", Review of Economic Studies, 54, 37-46.

[3] d'A spremont, C., Gabszewicz, J.J ., and Thisse, J.-F. (1979), "On Hotelling's 'Stability in Competition"', Econometrica, 47, 1045-1050.

[4] Eaton, B.C. (1976), "Free Entry in One-Dimensional Models: Pure Profits and Multiple Equilibria", J ournal of Regional Science, 16, 21-33.

[5] Eaton, B.C., and Lipsey, R.G. (1978), "Freedom of Entry and the Existence of Pure Pro..t", E conomic J ournal, 88, 455-469.

[6] Eaton, B.C., and Lipsey, R.G. (1980), "Exit Barriers are Entry Barriers: The Durability of Capital as a Barrier to Entry", Bell J ournal of Economics, 11, 721-729.

[7] Eaton, B.C., and Wooders, M.H. (1985), "Sophisticated Entry in a Model of Spatial Competition", RAND J ournal of Economics, 16, 282297.

[8] Harter, J .F.R. (1993), "Dixerentiated Products with R\&D", J ournal of Industrial Economics, 41, 19-28.

[9] Hay, D.A. (1976), "Sequential Entry and Entry-Deterring Strategies in Spatial Competition", Oxford E conomic Papers, 28, 240-257.

[10] J udd, K.L. (1985), "Credible Spatial Pre-E mptition", RA ND J ournal of Economics, 16, 153-166.

[11] Lambertini, L. (1997), "Unicity of the Equilibrium in the Unconstrained Hotelling M odel", R egional Science and Urban Economics, 27, 785-798. 
[12] Lane, W.J . (1980), "Product Dixerentiation in a Market with Endogenous Sequential Entry", Bell J ournal of Economics, 11, 237-260.

[13] Neven, D. (1987), "Endogenous Sequential Entry in a Spatial Model", International J ournal of Industrial Organization, 5, 419-434.

[14] Prescott, E.J ., and Visscher, M. (1977), "Sequential Location among Firms with Foresight", B ell J ournal of Economics, 8, 378-393.

[15] Schmalensee, R. (1978), "Entry Deterrence in the Ready-to-Eat Cereal Industry", B ell J ournal of Economics, 9, 305-327.

[16] Tabuchi, T., and J .-F. Thisse (1995), "A symmetric Equilibria in Spatial Competition", International J ournal of Industrial Organization, 13, 213227. 